\title{
Effects of fibre orientation on mechanical properties of hybrid bamboo/glass fibre polymer composites
}

\author{
B STANLY JONES RETNAM ${ }^{1, *}$, M SIVAPRAGASH ${ }^{1}$ and P PRADEEP ${ }^{2}$ \\ ${ }^{1}$ Department of Mechanical Engineering, ${ }^{2}$ Department of Automobile Engineering, \\ Noorul Islam Centre for Higher Education, Kumaracoil 629 180, India
}

MS received 25 June 2013; revised 7 November 2013

\begin{abstract}
The usage of natural fibre as reinforcement in polymer composites have widely increased because of its enhanced properties. The usage of plant fibre cannot alone satisfy all the needs of the composites. Hence, introduction of hybrid plays a vital role in enhancing the mechanical properties of the FRP composites. Fibre orientation contributes significant role in improving the mechanical properties of the FRP composites. In this proposal, hybrid bamboo/glass fibre woven in different orientations such as $0 \% 90^{\circ}$ and $\pm 45^{\circ}$ was used and its effect on mechanical properties were studied. Composites containing hybrid fibres found to possess better mechanical properties, when compared to pure bamboo. In order to justify this, the following mechanical properties such as tensile, flexural, impact and hardness were investigated. SEM analysis shows the bonding between the matrix and reinforcement. All the above test results indicate that the introduction of natural bamboo fibre in glass reduces the overall cost of the composites with no compromise in strength and also attracted several studies covering green technologies.
\end{abstract}

Keywords. Bamboo fibre; tensile strength; flexural strength; SEM.

\section{Introduction}

Composites reinforced with natural fibres received increasing interest from industries in a wide field of applications such as automobile, construction, aerospace and packing (Pickering et al 2007; Ku et al 2011). Natural fibres, when compared to glass fibres possess low density, low cost, consumes low energy, distributed worldwide, neutral to $\mathrm{CO}_{2}$, no abrasion to machining, no health risk when inhaled and since it is biodegradable, it can be easily disposed (Paul Wambua et al 2003). The main drawback of using natural fibre is their high level of moisture absorption, insufficient adhesion between untreated fibres and the polymer matrix which can lead to deboning with age (Gassan 2002). In order to increase the adhesion properties of natural fibre, the bamboo strips were subjected to different chemical treatments (Hongyan Chen et al 2011). By chemical modification (silane coupling), the mechanical properties of the composite such as tensile, flexural and impact strength increases due to improved adhesion between the polymer and bamboo fibre matrix (Sun-Young Lee et al 2009). Surface treatments of bamboo fibres improve interfacial bonding strength between fibres (Hongwa Ma and Chang Whan Joo 2011).

Bamboo fibre belongs to the family of grass. It is an enduring, versatile and highly renewable resource found

\footnotetext{
*Author for correspondence (er.stanleybjones@yahoo.co.in)
}

naturally on every continent except Europe. Among the well known natural fibres (jute, coir, straw, banana, etc.) bamboo has low density and high mechanical strength. The specific tensile strength and specific gravity of bamboo are considerably less than those of glass fibres. However, cost considerations makes bamboo an attractive material for reinforcement (Krishna Prasad Rajan et al 2011). Though, there are many advantages of natural fibres, there is also certain limitation such as lower modules, low strength and poor moisture resistance when compared to synthetic fibres (Jarukumjorn and Suppakar 2009). One main way to enhance the mechanical property of the composite can be done by reinforcement by two or more variety of fibres in a single matrix, leading to hybrid composites with greater diversity.

It was observed that the tensile, flexural and impact strength increased with the increase in fibre loading up to $30 \%$, above which, there was a significant reduction in the mechanical strength. The treated composites showed better properties when compared with non-treated composites (Smita Mohanty et al 2006). Enhancement of material performance depends entirely on interfacial bond strength between the fibre and matrix (Karger-Kocsis 1995). The stress-strain behaviour, strength, ductility, and failure mode of FRP composites depend on fibre orientation (Guoqiang Li et al 2006). Woven composites exhibit higher flexural and impact properties due to different structures in cross-section. Composites reinforced with woven fabric have better out-of-plane stiffness, 
strength and toughness and easier handling in production than unidirectional composites (Mariatti et al 2008). Woven fibres possess good surface with pleasing appearance. Research on pure bamboo/hybrid fibre with respect to fibre orientation is relatively new. The main aim of this research was to investigate possible mechanical properties of pure bamboo and hybrid FRP composite with respect to fibre orientation. The results were compared with each other to find the best among them.

\section{Experimental}

\subsection{Materials}

The natural fibres of bamboo of diameter $10 \mu \mathrm{m}$ and glass fibre of diameter $5 \mu \mathrm{m}$ were used in this study. To enhance the properties of bamboo fibre, it was chemically treated with silane. The bamboo fibres in dried form were woven by weaving machine to the size of moulding box $200 \times$ $150 \mathrm{~mm}$. The glass fibres in the form of woven were used for composite fabrication. Polyester resin as matrix, cobalt napthanate and methyl ethyl ketone peroxide were used as oxidizer and catalyst, respectively.

\subsection{Preparation of composites}

Moulding box of required size $200 \times 150 \times 10 \mathrm{~mm}$ was made in wood and the inner portion of the moulding box was coated with wax polish, which acts as a releasing agent. Two different types of plates were made. Figures 1 and 2 show the pure bamboo reinforced with polyester matrix and the other with bamboo/E-glass hybrid fibre with polyester resin combination. The method adopted for fabricating composite plates was hand lay-up process. Polyester resin was mixed with required amount of cobalt napthanate as oxidizer and then with catalyst, methyl

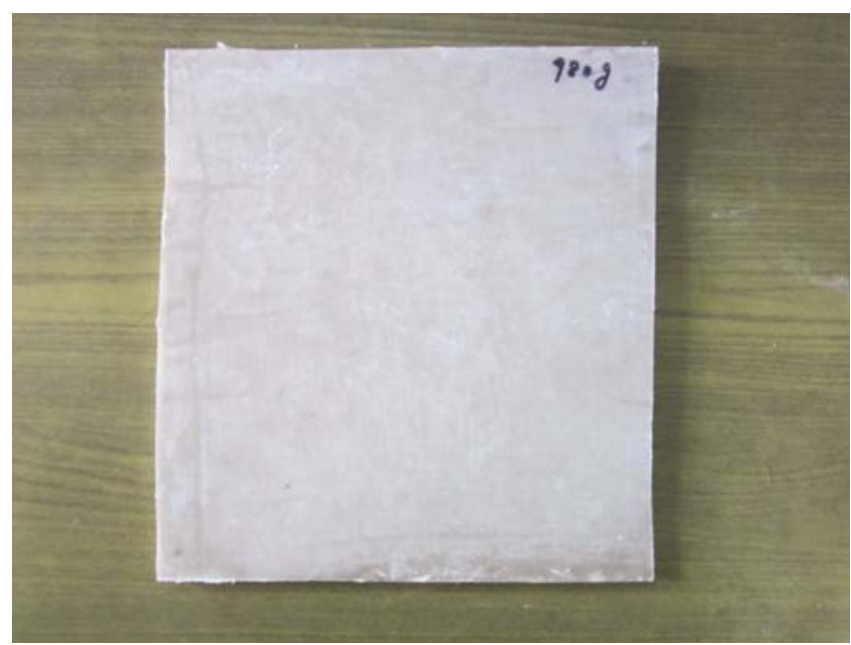

Figure 1. Woven bamboo fibre plate. ethyl ketone peroxide. The bamboo fibre woven was placed and then the required amount of polyester resin was poured over it. The process continued until the required thickness and volume percentage of fibre was obtained. For each time, a roller was used to roll over the fibre in order to remove the air bubbles from it. Hybrid FRP composite plates preparation also done in the same way, but the placing of fibres was done alternatively one over the other, i.e. one layer of woven pure bamboo fibre followed by E-glass fibre mat. After the required thickness and volume fraction were obtained, the composite plates were allowed to dry at room temperature for $24 \mathrm{~h}$. Then, the FRP composite plates were removed from the mould.

\subsection{Mechanical testing}

The plates of pure bamboo and hybrid FRP composites were then cut into specimens as per ASTM standards for conducting different tests. For obtaining different orientations, the specimens were made as templates in GI sheets and are drawn on the plates with appropriate angles. Then, the plates are cut into different angles using milling cutter along the fibre orientation, say $0^{\circ} / 90^{\circ}$ or $\pm 45^{\circ}$ as shown in figure 3.

Tensile test of bamboo and hybrid FRP composites were performed using computerized servo-controlled UTM machine with specimen standard ASTM D 638 as shown in figure 4 . The cut specimens were fixed in the UTM, the gauge length and cross head speeds were fixed to 5 and $2 \mathrm{~mm} / \mathrm{min}$, respectively.

Flexural test was conducted on computerized UTM using special attachment with specimen standard ASTM D 790 as shown in figure 5. The span to depth ratio was fixed as $16: 1$ and the speed of test was set as $2 \mathrm{~mm} / \mathrm{min}$.

Impact test were carried out using a Charpy impact testing machines with specimen standards ASTM D 6110

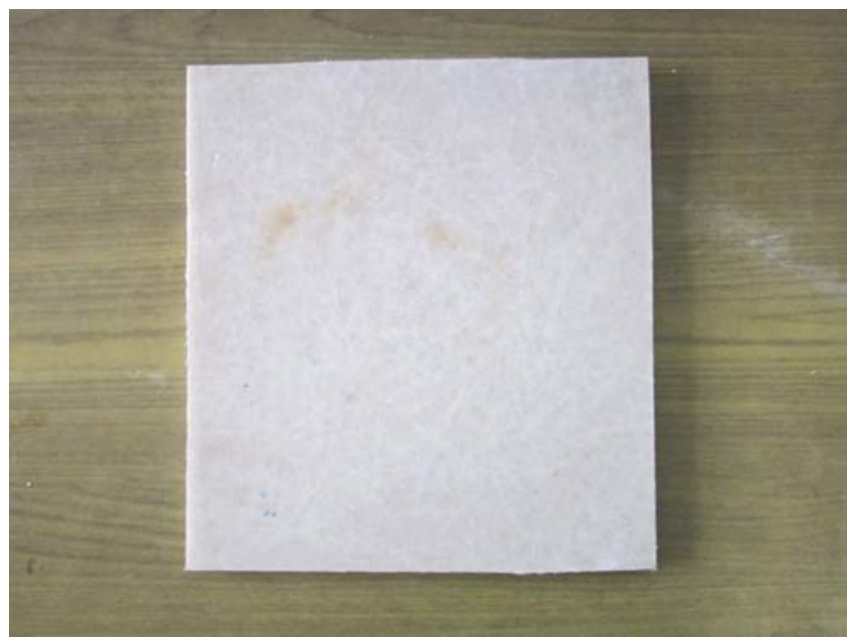

Figure 2. Hybrid fibre plate. 
as shown in figure 6 . The fracture values were calculated by dividing the energy by cross-sectional area of the specimen.

Hardness test was conducted by using a Rockwell hardness tester as per specimen standard ASTM D 785 shown in figure 7 . A standard specimen of $6.4 \mathrm{~mm}$ thickness was cut from the plate irrespective of its size. Load was applied for $15 \mathrm{~s}$ and the hardness was measured. All the values were taken as the average of 3 samples each.

Morphology of the fibres was observed by scanning electron microscope (SEM). The specimen for SEM test is shown in figure 8. Magnification of $50 \mu \mathrm{m}$ is taken for the study.

\section{Results and discussion}

\subsection{Properties of bamboo and E-glass fibre}

The measured tensile properties of bamboo and E-glass fibre are shown in table 1, in comparison with other natural

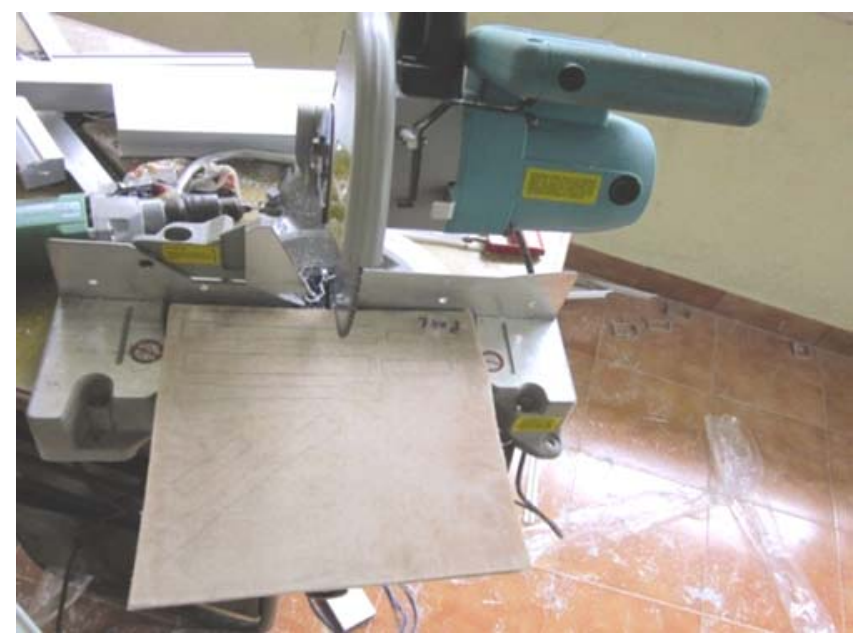

Figure 3. Cutting specimens using milling cutter.

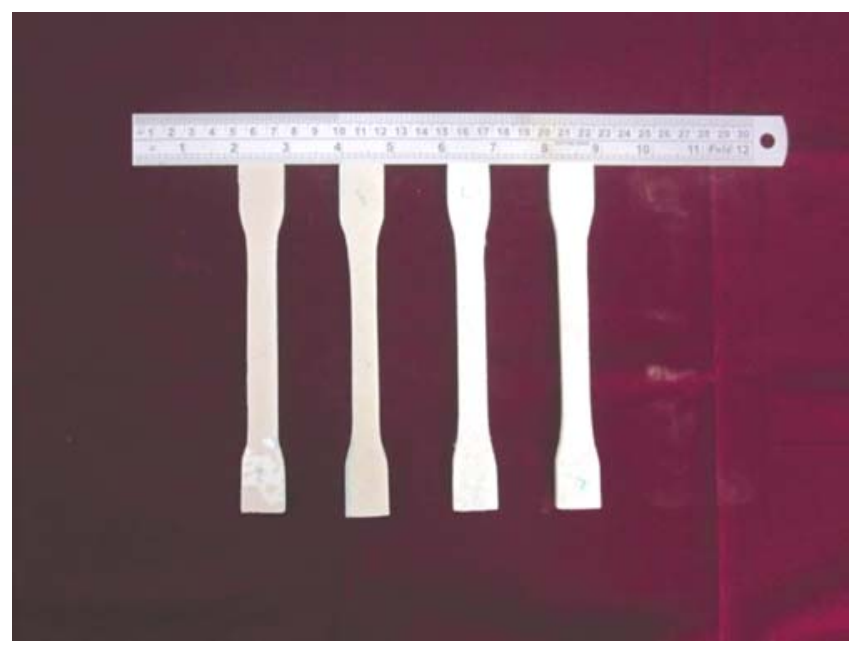

Figure 4. Tensile specimens. fibres, such as banana and pandanus which exhibit higher properties when compared with kenaf, bagasse, sisal and pineapple. Normally, the properties of natural fibres depend on species, maturity and extraction (Mariatti et al 2008).

\subsection{Effects of fibre orientation on pure bamboo and hybrid fibre}

3.2a Tensile stress-strain: Figure 9 shows the tensile stress-strain curve of pure bamboo and hybrid FRP composites with respect to fibre orientation $\left(0^{\circ} / 90^{\circ}\right.$, $\pm 45^{\circ}$ ). Among all the combinations, the hybrid FRP composites with $\pm 45^{\circ}$ orientation exhibited high tensile strength, when compared with other combination. Further, the other combinations such as hybrid with $0^{\circ} / 90^{\circ}$ orientation and pure bamboo with $0^{\circ} / 90^{\circ}, \pm 45^{\circ}$ orientation showed a very significant increase in tensile strength,

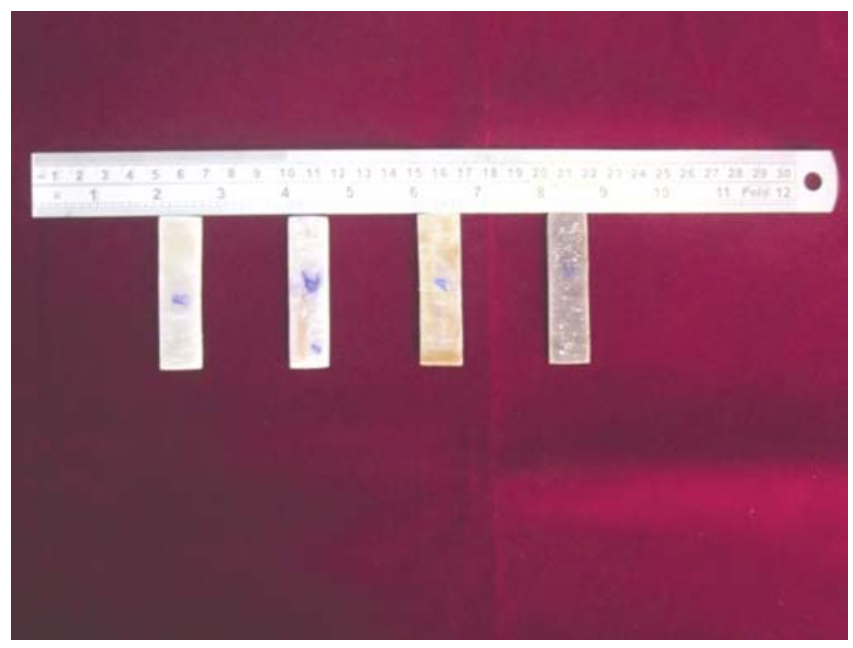

Figure 5. Flexural specimens.

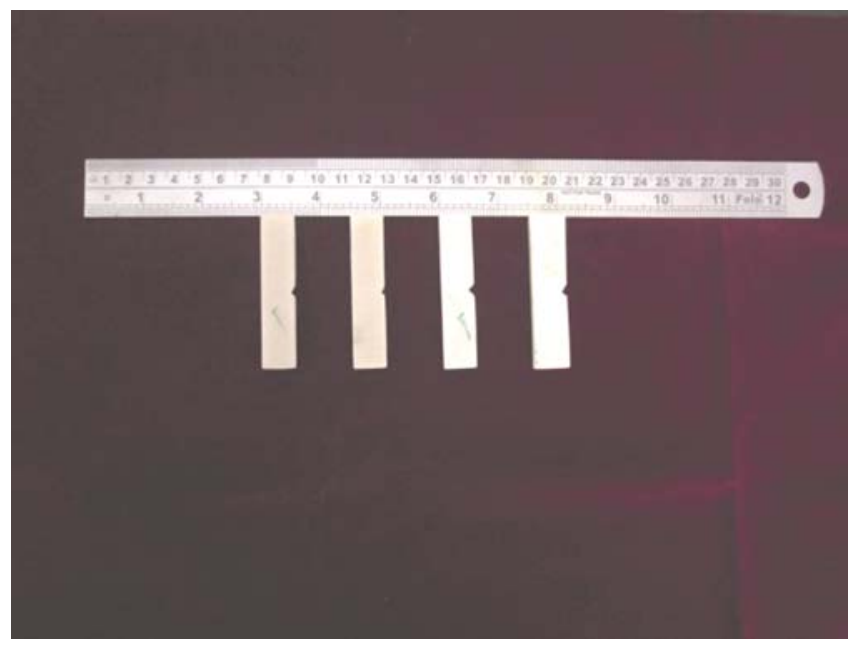

Figure 6. Impact specimens. 
Table 1. Tensile properties of bamboo and E-glass fibres in comparison with other natural fibres.

\begin{tabular}{lcccc}
\hline Fibres & $\begin{array}{c}\text { Fibre diameter } \\
(\mu \mathrm{m})\end{array}$ & $\begin{array}{c}\text { Tensile strength } \\
\left(\mathrm{N} / \mathrm{mm}^{2}\right)\end{array}$ & $\begin{array}{c}\text { Tensile modulus } \\
\left(\mathrm{N} / \mathrm{mm}^{2}\right)\end{array}$ & $\begin{array}{c}\text { Strain at break } \\
(\%)\end{array}$ \\
\hline E-glass & $5-26$ & 3446 & $72 \cdot 3$ & $4 \cdot 8$ \\
Bamboo & $10-330$ & 440 & 35 & $1 \cdot 4$ \\
Banana & $70-330$ & 355 & $33 \cdot 8$ & $5 \cdot 3$ \\
Pandanus & $80-260$ & 135 & 46 & $4 \cdot 6$ \\
\hline
\end{tabular}

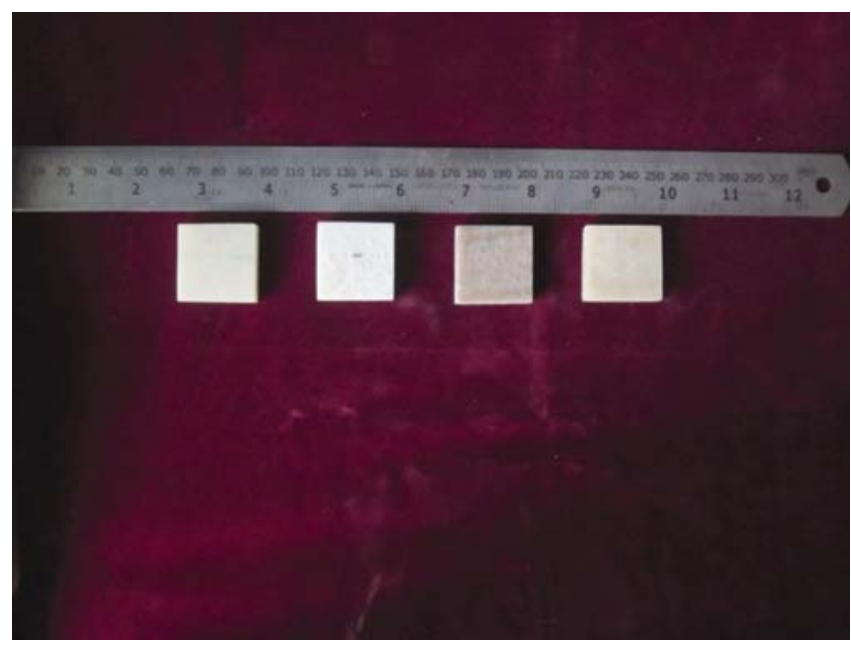

Figure 7. Hardness specimens.

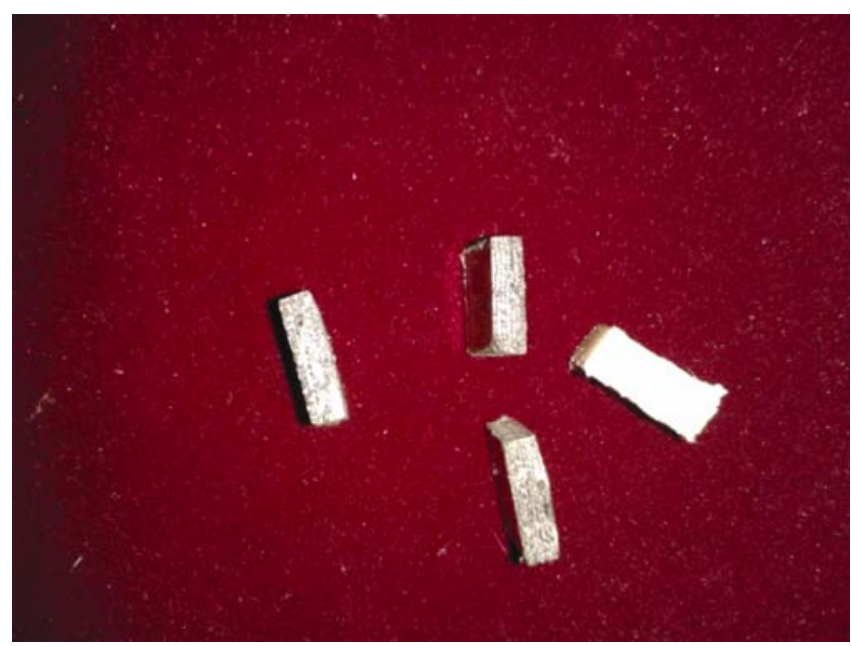

Figure 8. SEM specimens.

when compared to non-woven bamboo strip mat and glass hybrid fibre (Pradeep and Rakesh Kumar 2010).

SEM has been done to investigate the surface morphology of the fibres with respect to bonding on the tensile specimens after breakage. The cross-section of pure bamboo and hybrid FRP composites with respect to orientation is shown in figures $10(\mathrm{a}-\mathrm{d})$. It was observed that hybrid fibre shows more densified and compact structure than the pure bamboo fibre. Thus, the tensile, flexural,

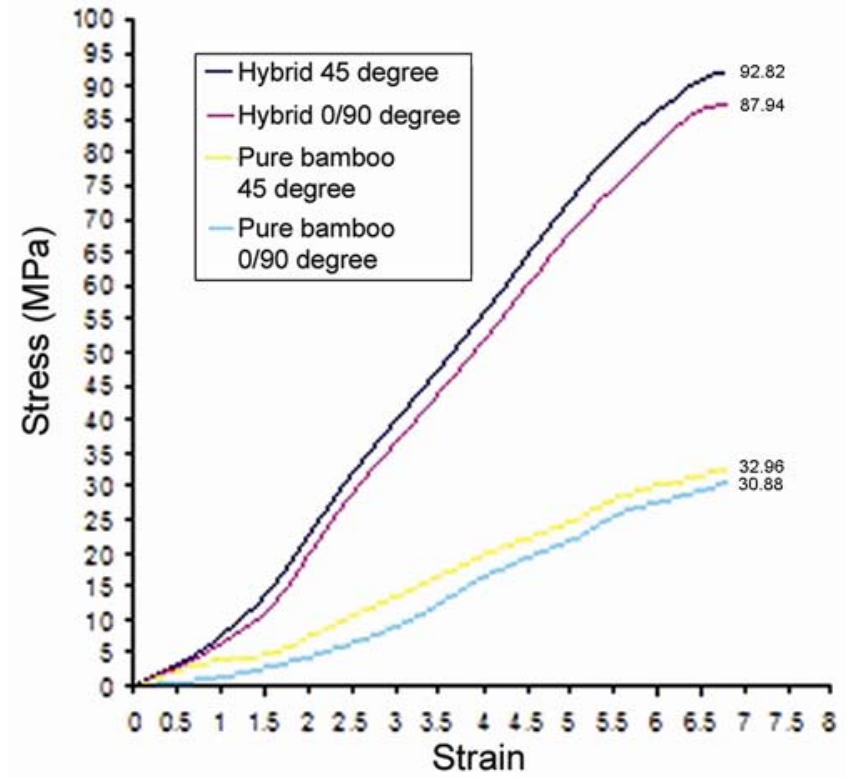

Figure 9. Tensile stress-strain curve.

impact and hardness properties of hybrid composites were higher, when compared with pure bamboo fibre composites. From figure 10 (a) and (c) for $0^{\circ} / 90^{\circ}$ orientation for both combinations, relatively long fibres were observed. The crack path is changed by the fibre orientation and directed along the fibre surface. This leads to fibre debonding, which is an indication of matrix separation around the fibres as crack front intersects the fibre/ matrix interface. Subsequently, it causes fibre pull-out and creates energy dissipation by shear. Furthermore, fibre end damage and fibre split were observed and in Wonga et al (2010), the same was identified. The figure 10 (b and d) of $\pm 45^{\circ}$ orientation reveals no formation of fibre debonding, pull out, end damage and split.

3.2b Flexural strength: Figure 11 shows the flexural strength of pure bamboo and hybrid FRP composites with respect to fibre orientation $\left(0^{\circ} / 90^{\circ}, \pm 45^{\circ}\right)$. Flexural strength of woven hybrid FRP composites with $\pm 45^{\circ}$ orientation shows higher strength when compared to other combinations including flexural strength of reformed bamboo which has 276.6 MPa (Wonga et al 2010).

3.2c Impact strength: Figure 12 shows the Charpy impact strength of pure bamboo and hybrid FRP 

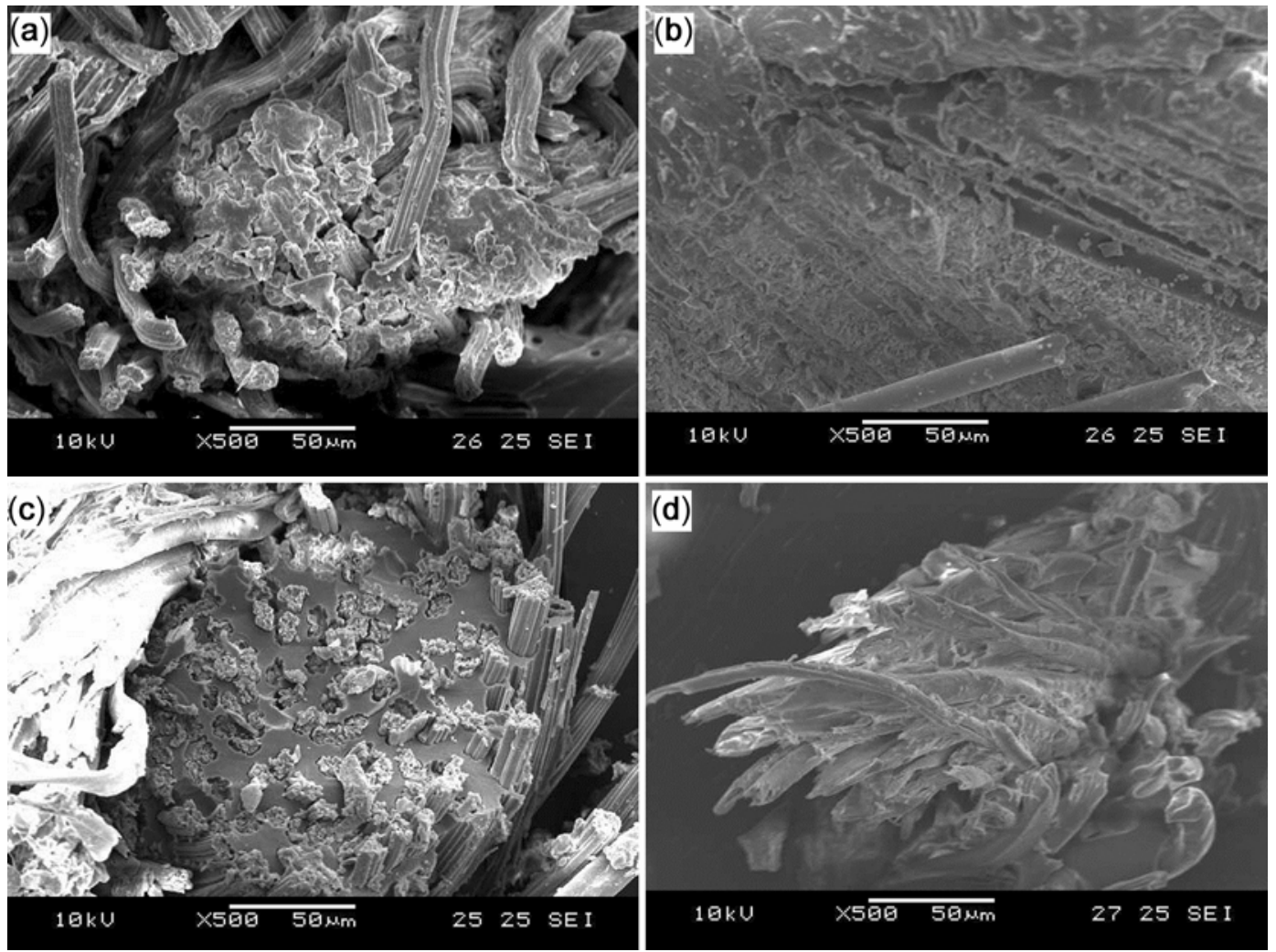

Figure 10. SEM images of pure bamboo FRP composites with respect to (a) $0^{\circ} / 90^{\circ}$ orientation and (b) $\pm 45^{\circ}$ orientation. SEM images of hybrid FRP composites with respect to (c) $0 \% / 90^{\circ}$ orientation and (d) $\pm 45^{\circ}$ orientation.

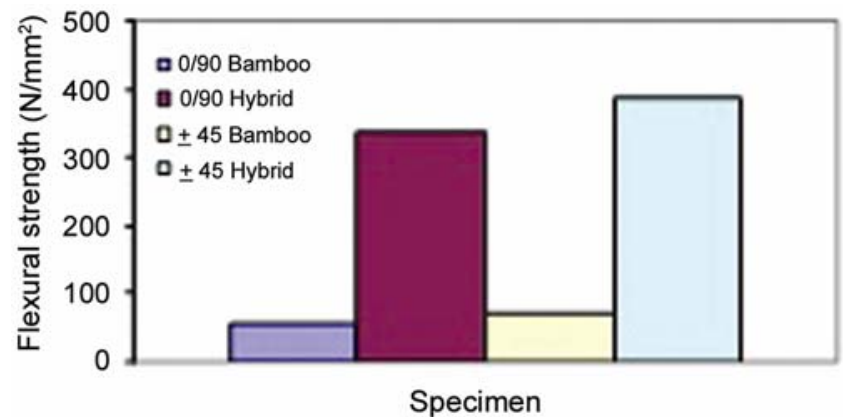

Figure 11. Specimen vs flexural strength.

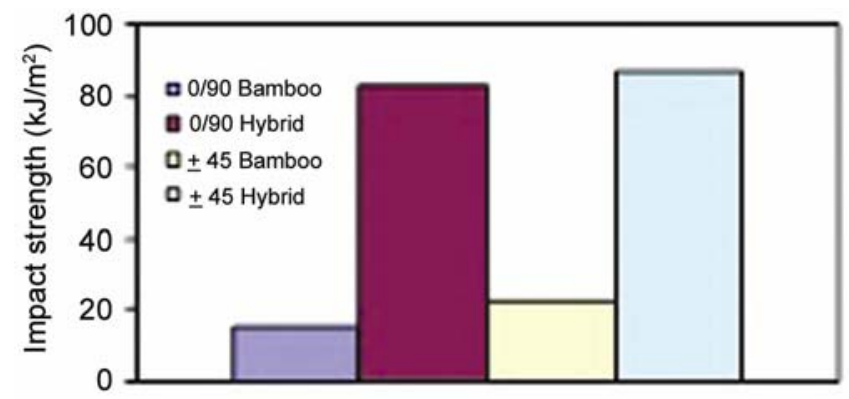

Specimen

Figure 12. Specimen vs impact strength.

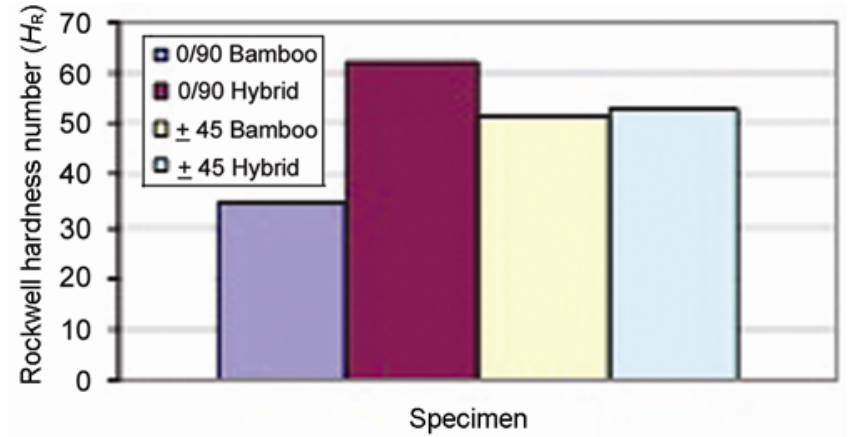

Figure 13. Specimen vs Rockwell hardness number.

composites with respect to fibre orientation $\left(0^{\circ} / 90^{\circ}\right.$, $\left.\pm 45^{\circ}\right)$. Though, the packing between the fibres were very close, all the combinations exhibit very good impact strength. But, when compared to pure bamboo FRP composites, the hybrid composites expressed very high impact strength. Higher values of impact strength were observed in hybrid FRP with $\pm 45^{\circ}$ orientation. It is well known that the impact response of fibre composites is highly influenced by the interfacial bond strength, the matrix and fibre properties. Impact energy is dissipated by debonding, fibre and/or matrix fracture and fibre pullout. Fibre fracture dissipates less energy compared to 
fibre pull-out. The former is common in composites with strong interfacial bond, while the occurrence of the latter is a sign of a weak bond (Paul Wambua et al 2003). Hence, hybrid fibres possess very good impact strength.

3.2d Hardness number: Figure 13 shows Rockwell hardness number for pure bamboo and hybrid FRP composites with respect to fibre orientation $\left(0^{\circ} / 90^{\circ}, \pm 45^{\circ}\right)$. The hybrid fibres expressed very good hardness values when compared to pure bamboo FRP composites. The glass fibre used here, was in the form of mat and it was loosely packed. Hence, uniform values were not obtained in all the parts of the specimen. However, the average of three values was taken for the hardness value. The obtained average results of hybrid FRP were higher, when compared to pure bamboo FRP. In this, the fibres with $0^{\circ} / 90^{\circ}$ and $\pm 45^{\circ}$ showed not much influence on hardness value.

\section{Conclusions}

(I) The hybrid specimen with $\pm 45^{\circ}$ orientation yielded a tensile strength of $92.26 \mathrm{~N} / \mathrm{mm}^{2}$, flexural strength of $387 \cdot 725 \mathrm{~N} / \mathrm{mm}^{2}$, which was higher when compared with others. The hybrid specimen with $\pm 45^{\circ}$ orientation possesses a flexural strength of $387.725 \mathrm{~N} / \mathrm{mm}^{2}$ impact strength of $87 \mathrm{~kJ} / \mathrm{m}^{2}$, which was higher when compared with others.

(II) Hardness test reveals that the hybrid specimen with $0^{\circ} / 90^{\circ}$ orientation shows a hardness number of $62 \cdot 3 \mathrm{H}_{\mathrm{R}}$. (III) SEM test reveals that the hybrid specimens possess densified bonding, when compared to pure bamboo composite alone.

(IV) The above experiments reveal that the hybridization of the composites increases the mechanical properties by increasing the bonding strength between the fibre and polyester resin. An orientation of $\pm 45^{\circ}$ helps to boost up the mechanical properties of the composites.

\section{References}

Gassan J 2002 Composites: Part-A: Appl. Sci. Manufac. 33 369

Guoqiang Li, Dinesh Maricherla, Kumar Singh, Su-Seng Pang and Manu John 2006 Compos. Struct. 74475

Hongwa Ma and Chang Whan Joo 2011 J. Compos. Mater. 45 2455

Hongyan Chen, Menghe Miao and Xin Ding 2011 J. Compos. Mater. 451533

Jarukumjorn K and Suppakar N 2009 Composites (Part B) 40 623

Karger-Kocsis J 1995 Polypropylene: Structure, blends and composites (London, UK: Chapman and Hall)

Krishna Prasad Rajan, Veena N R, Hanna J Maria, Rathish Rajan, Mikad Skritvars and Kuruvilla Joseph 2011 J. Compos. Mater. 451325

Ku H, Wang H, Pattarachaiya Koop N and Trada M A 2011 Compos. (Part B) 42856

Mariatti M, Jannah M, Abu Bakar A and Abdul Khalil H P S 2008 J. Compos. Mater. 42931

Paul Wambua, Jan Ivens and Ignaas Verpoest 2003 Compos. Sci. Technol. 631259

Pickering K L, Beckermann G W, Alam S N and Foreman N J 2007 Optimiz. Compos. Part - A: Appl. Sci. Manufac. 38461

Pradeep K, Kushwaha and Rakesh Kumar 2010 J. Reinforce. Plast. Compos. 291952

Smita Mohanty, Sushil K Varma and Sanjay Nayak K 2006 Compos. Sci. Technol. 66538

Sun-Young Lee, Sang-Jin Chun, Geum-Hyun Doh and In-Aeh Kang 2009 J. Compos. Mater. 431639

Wonga K J, Zahi S, Low K O and Lim C C 2010 Malaysia Mater. Des. 314147 